\title{
BNCC: disputa pela qualidade ou submissão da educação?
}

\author{
BNCC: dispute for quality or submission of education? \\ BNCC: ¿disputa por la calidad o submisión de la educación?
}

VERA MARIA VIDAL PERONI

MARIA RAQUEL CAETANO

LISETE REGINA GOMES ARELARO

\begin{abstract}
Resumo: Este artigo aborda a relação entre público e privado e os sujeitos que atuaram na elaboração da Base Nacional Comum Curricular-BNCC: neoliberais e neoconservadores ligados a diferentes instituições. A educação básica passa a ser alvo dos interesses desses grupos, que visam a influenciar o conteúdo da educação e direcionar as políticas educacionais. Os dados foram levantados através de análise documental, pesquisas já realizadas, sites, estabelecendo relações entre o público e o privado na BNCC. Os resultados apontam para a educação como espaço de disputa de projetos distintos e antagônicos.
\end{abstract}

Palavras-chave: BNCC, público-privado, políticas educacionais.

Abstract: This paper discusses the relationship between public and private and the subjects that worked in the elaboration of the National Curricular Common Base - BNCC: neoliberalists and neoconservatives linked to different institutions. The basic education is the target of the interests of these groups, which aim to influence the content of education and direct education policies. The data were collected through documental analysis, surveys previously done, websites, establishing relationships between the public and the private at the BNCC. The results suggest an education as a space of dispute about distinct and antagonists projects.

Keywords: BNCC, public-private, educational policies.

Resumen: Este artículo aborda la relación entre lo público y lo privado, y los sujetos que actuaron en la elaboración de la Base Nacional Común CurricularBNCC: neoliberales y los neoconservadores de diferentes instituciones. La educación básica pasa a ser objeto de los intereses de esos grupos que buscan influir en el contenido de la educación y direccionar las políticas educativas. Los datos fueron levantados a través de análisis documental, investigaciones ya realizadas, sitios electrónicos, estableciendo relaciones entre lo público y lo privado en la BNCC. Los resultados muestran la educación como espacio de disputa de proyectos distintos y antagónicos.

Palabras clave: BNCC, público-privado, políticas educativas 


\section{INTRODUÇÃO}

Vivemos um processo de intensificação da privatização do público, que é parte de uma correlação de forças por projetos societários. O texto aqui apresentado tem como base pesquisas desenvolvidas sobre o tema em um contexto de crise do capital, e suas estratégias de superação, que redefinem o papel do Estado para com as políticas sociais, com profundas implicações para a democracia e, de como se materializam nas etapas e modalidades da educação básica brasileira. Aqui trataremos de dois grupos de sujeitos vinculados ao mercado e ao neoconservadorismo, tentando entender com maior profundidade quem são, suas semelhanças e diferenças, como se relacionam e qual é o conteúdo de suas propostas

Entendemos que a relação entre público e privado na política educacional é parte constitutiva das mudanças sociais e econômicas. Assim que, não se trata de uma contraposição entre Estado e sociedade civil, já que entendemos que, conforme a concepção de Thompson (1981), ambos são construídos por sujeitos individuais e coletivos ${ }^{1}$, em um processo histórico de correlação de forças perpassados por interesses mercantis. Portanto, em nossas pesquisas, o privado é vinculado ao mercado e ao neoconservadorismo, com implicações para a democratização da educação.

Democracia é aqui entendida como materialização de direitos e de igualdade social ${ }^{2}$ e coletivização das decisões ${ }^{3}$ com efetiva participação na elaboração de políticas com base na prática social crítica e autocrítica no curso de seu desenvolvimento ${ }^{4}$.

É importante ressaltar a especificidade brasileira na análise das redefinições do papel do Estado, pois os avanços das lutas por direitos sociais ocorreram no momento pós-ditadura, na década de 1980, mesmo período de crise capital (MÉSZÁROS, 2002; HARVEY, 1989). Período em que o capitalismo propunha um conjunto de estratégias para retomar o aumento das taxas de lucro, reduzindo direitos, com graves consequências para a construção da democracia e da efetivação dos direitos sociais, materializados em políticas públicas.

Vivemos a contradição de que, ao mesmo tempo em que a privatização do público é cada vez maior, também, em um processo de correlação de forças, no período pós ditadura, avançamos lentamente em alguns direitos materializados em

1 Sujeitos individuais e coletivos na concepção de Thompson (1981).

2 Sobre a não separação entre o econômico e o político, ver Wood (2003).

3 Coletivização das decisões conforme Vieira (1998).

4 Ideia desenvolvida por Mészáros (2002) em texto que fala sobre o controle social e como este deve ocorrer enquanto processo e realizado pelos próprios executores da política social. 
políticas educacionais. Trata-se de direitos que foram reivindicados no processo de democratização, nos anos 1980, e materializados em parte na Constituição Federal de 1988 e na Lei de Diretrizes e Bases da Educação Nacional (LDB) de 1996, como a gestão democrática da educação, a educação básica entendida como educação infantil, fundamental e média, a gratuidade da educação pública nos estabelecimentos oficiais, entre outros.

Ao mesmo tempo, vivemos o que chamamos em nossas pesquisas, de um processo de "naturalização do possível", em que a população, que mal tinha iniciado a luta por direitos sociais para todos e com qualidade, acaba aceitando políticas focalizadas "para evitar o caos social", priorizando populações em vulnerabilidade social e nem sempre oferecidas pelo poder público.

\section{SUJEITOS INDIVIDUAIS E COLETIVOS QUE ATUAM NAS POLÍTICAS EDUCACIONAIS}

Por sujeitos individuais e coletivos, faz-se necessário considerá-los na perspectiva de Thompson (1987), a partir de relações estruturadas em termos de classe que ocorrem nas relações humanas e nas formações econômicas, históricas e culturais, com capacidade de percepção e articulação de interesses de alguns indivíduos contra outros, cujos interesses diferem dos seus. "A consciência de classe é a forma como essas experiências são tratadas em termos culturais: encarnadas em tradições, sistemas de valores, ideias e formas institucionais." (Thompson, 1987, v.1, p. 10). Os sujeitos coletivos tornam-se conscientes dos seus interesses comuns e desenvolvem formas apropriadas de organização e ação comuns, são homens e mulheres que pensam e agem a partir de determinada realidade e, conforme diz Thompson, respondem, individualmente ou em grupo. Com essa perspectiva metodológica, apresentaremos as relações entre o público e o privado que se estabelecem na BNCC e as intervenções na direção e conteúdo da política educacional.

São várias as formas como o privado tem atuado no setor público. Verificamos em nossas pesquisas o quanto a relação entre o público e o privado é complexa e multifacetada. Entendemos que a mercadificação da educação pública não é uma abstração, mas ocorre via sujeitos e processos. Algumas instituições têm fins lucrativos e outras não, ou não claramente, mas é importante destacar que entendemos as redes como sujeitos (individuais e coletivos) em relação, com projeto de classe. 
No Brasil, entre os interlocutores do governo federal, nos anos 1990, estava o Instituto Herbert Levy, que apresentou sua proposta de educação para o governo brasileiro em 1992. É interessante destacar que a elaboração da proposta contou, já na época, com o apoio do MEC, através da organização do 'Seminário Ensino Fundamental \& Competitividade Empresarial', em 1992. Os empresários propunham participar ativamente da elaboração das políticas educacionais, influenciando mais as políticas do que gerindo diretamente as escolas: "Complementa[m] a ação do governo, queimando, em defesa de seus próprios interesses econômicos, etapas do processo de otimização do ensino brasileiro." (OLIVEIRA; CASTRO, 1993, p. 6).

Verificamos que a decisão de participar de forma mais contundente da direção e execução das políticas educacionais já havia se iniciado naquela época, de forma organizada, pelos empresários, que propunham participar ativamente da elaboração das políticas educacionais, influenciando mais as políticas do que gerindo escolas diretamente. Tal processo se intensificou nas décadas seguintes, conforme trataremos neste artigo.

\section{AS INTERVENÇÕES NO CONTEÚDO DAS POLÍTICAS EDUCACIONAIS}

O processo de mercantilização ocorre também com o privado definindo o conteúdo da educação. Observamos, em parte, o poder público assumindo a lógica do privado na administração pública, através da gestão gerencial e, também, quando abre mão de decidir o conteúdo da educação, repassando a direção para instituições privadas. Nesse caso, a propriedade permanece pública, mas a direção do conteúdo das políticas educativas é repassada para o setor privado. As instituições públicas, se democráticas, são permeáveis à correlação de forças, com processos decisórios em que não se tem previamente o controle do produto. São instituições de propriedade pública, mas se o processo decisório está ausente, já que tudo é previamente definido e monitorado por uma instituição privada e os professores apenas executam tarefas, entendemos que este também é um processo de privatização da educação.

Semelhante processo de privatização do público tem consequências para a democratização da educação, pois concordamos com Vieira (1998, p. 12) quando diz que "Não há estágio democrático, mas há processo democrático pelo qual a vontade da maioria ou a vontade geral vai assegurando o controle sobre os interesses da administração pública.”. Afirma também: “Quanto mais coletiva a decisão, mais democrática ela é. Qualquer conceito de democracia, e há vários deles, importa em grau crescente de coletivização de decisões." (VIEIRA, 1998, 
p. 12). No entanto, a coletivização das decisões como parte da construção do processo democrático foi cada vez mais subsumida pelo processo de privatização da educação

\section{NEOLIBERALISMO E NEOCONSERVADORISMO}

As mudanças nas fronteiras entre o público e o privado ocorrem como parte de um contexto, em que as estratégias de superação da crise - globalização, neoliberalismo e reestruturação produtiva, Terceira Via - redefinem o papel do Estado.

As teorias que afirmam que a crise está no Estado, como Neoliberalismo e Terceira Via (atual social democracia), trazem implicações para as políticas sociais, pois transferem do poder público para o mercado, parte da coordenação societária, não apenas a execução, mas também a direção das políticas. $O$ que permanece no âmbito do Estado acaba sofrendo a lógica gerencial, que trazem princípios do mercado para a gestão pública.

Enfim, o Neoliberalismo provoca o caos social e o neoconservadorismo responde com maior repressão para "colocar a casa em ordem".

O aumento do desemprego, dos ajustes estruturais que minimizam as políticas sociais e a exacerbação da competitividade e individualismo, pode provocar caos social e civilizatório e a este risco o neoconservadorismo responde com maior repressão. (...)

E com valores morais centrados no nacionalismo cultural, na retidão moral, no cristianismo (de uma certa moralidade evangélica) nos valores familiares e em questões de direito à vida, assim como no antagonismo a novos movimentos sociais como o feminismo, os direitos homossexuais, a ação afirmativa e o ambientalismo (Harvey, 2008, p. 94).

Harvey (2008) trabalha, também, com as semelhanças e diferenças entre neoliberalismo e neoconservadorismo. Quanto às semelhanças, neoconservadores e neoliberais são favoráveis: ao poder corporativo, à iniciativa privada, à restauração do poder de classe, à desconfiança da democracia, a governança pela elite. Quanto às diferenças, o autor destaca a preocupação com a ordem em resposta ao caos e a defesa de uma moralidade inflexível como cimento social.

No caso brasileiro, o conservadorismo foi uma marca da nossa história (Fernandes, 1987; Kaysel, 2015). Sobre o período pós ditadura, Fernandes (1985) adverte que a "Nova República não combateu de frente a ditadura e que um pacto conservador cortou a trajetória democrática" (p. 21) e que "as elites e o capital internacional temem mudanças rápidas em que podem perder o controle". (Ibidem, p. 23). A estrutura de classes da sociedade civil sob o capitalismo selvagem 
não comporta avanços, pois as classes dominantes precisam de um Estado forte para preservar a ordem e reproduzir seu poder real, e assim, lutam com afinco por um capitalismo de tipo ditatorial.

Neste sentido, foi fundamental impediro deslocamento de poder barrando as Diretas Já, esvaziando a praça pública para restabelecer o "mandonismo". A transferência de poder, se converteu em uma transferência de nomes, ocorrendo o que o autor chama de mudancismo, que acontece quando "o conservador chega à mudança social para preservar e fortalecer a ordem” (Idem, p. 71). Ocorreu assim, o que o autor chama de "conciliação pelo alto" (Idem, p. 72), em que a oposição consentida se tornou conciliadora, com mudanças pelo alto para sua continuidade.

Em agosto de 2016, após um processo sumário e bastante discutível, em termos legais e jurídicos, a presidenta eleita Dilma Roussef sofreu impeachment pelo Congresso Nacional, que, em menos de 24 horas, considerou legal as "pedaladas" dadas pelo seu sucessor e vice, Michel Temer, razão apresentada para sua cassação. Um novo golpe acontecia no Brasil, agora com o aval do Supremo Tribunal Federal.

Miguel (2016), observa que o golpe de 2016 marca uma fratura irremediável no experimento democrático iniciado no Brasil em 1985. Para o autor, a democracia é um conceito em disputa. O impedimento da presidenta foi uma afronta aberta às regras estabelecidas e marcou a ruptura do entendimento de que o voto é o único meio legítimo de alcançar o poder.

Para Boito (2016), o golpe foi o resultado de um conflito redistributivo de classe. Conforme o autor, de 2006 a 2012, o país vivenciou o neodesenvolvimentismo, e, em 2014, com a crise internacional, ele entrou em declínio. Quanto à relação neodesenvolvimentismo e neoliberalismo, o autor aponta que três acontecimentos foram responsáveis para a vitória da direita conservadora: a classe média como força ativa e militante na rua, a deserção da burguesia interna da frente neodesenvolvimentista e o recuo do governo Dilma diante da ofensiva restauradora. $\mathrm{O}$ autor conclui que a frente neodesenvolvimentista entrou em crise e, com ela, o governo que a representava.

Lowy (2016), aponta que a história mundial nos dois últimos séculos viveu um Estado de exceção; a democracia é que foi excepcional, já que, sempre foi considerada um peso para o Estado, para as classes dominantes e o capital financeiro. $\mathrm{O}$ autor adverte que, no Brasil, mesmo a democracia de baixa intensidade foi intensa demais para as classes dominantes e o capital financeiro. 
Em um processo de correlação de forças, a chamada nova direita se fortaleceu. Conforme o Instituto Liberal, em sua página da internet na matéria "Quem é a Nova Direita? O que ela pensa? E por que os "intelectuais" a temem tanto?”, apresenta algumas de suas ideias:

Valorização do indivíduo e da família como unidade básica da sociedade, isto é, a direita quer menos poder para o Estado e mais poder para o indivíduo. A direita não gosta de coletivos (tais como sindicatos) tomando decisões que deveriam ser tomadas pelo indivíduo. [...] Isto ocorre por causa de nossa desconfiança na capacidade do Estado. Logo, para evitar grandes rupturas da ordem, o melhor é que a mudança seja sempre gradual. Assim, sempre será possível corrigir eventuais erros antes que os mesmos se transformem em catástrofes (Disponível em: <https:// www.institutoliberal.org.br/blog/quem-e-nova-direita-o-que-ela-pensa-e-por-queos-intelectuais-temem-tanto/>. Acesso em 3 de julho de 2018).

É importante destacar que o próprio Instituto Liberal apresenta o conteúdo da proposta da nova direita e as vincula ao conservadorismo. O Instituto Liberal está vinculado em uma grande rede de think tanks que tem influenciado o cenário político internacional. Para Moraes (2015, p. 236) “eles existem para modelar as condições de possibilidade e de visibilidade das políticas. Para construir, nas mentes e nos corações dos indivíduos, aquilo que devem considerar crível e factível. (...)Tentam modelar o ambiente geral da política, a agenda.”

Nesta nova conjuntura, não apenas os think tanks se tornaram elementos centrais do "fazer politica". Já eram assim. Eles se transformaram, radicalizando bastante o papel que já vinham desenhando nos anos 1970. Mais ainda do que nos anos 197080, os think tanks da "novíssima direita" têm se tornado, cada vez mais, elementos fundamentais não para fornecer respostas a questões colocadas diante dos cidadãos. [...]E isso ocorre de modo deliberado, como uma estratégia política clara: a "novíssima direita" cria e multiplica think tanks e aparatos de mídia (impressa, eletrônica, virtual etc.) para modelar o ambiente político. De outro lado, operando também como lobbies (pressionando para aprovação de certas políticas ou para o direcionamento das já existentes), eles conseguem esse mesmo objetivo: policies make polity, diz a sentença (MORAES, 2015, p. 240).

Ao longo de muitos anos pesquisamos processos de privatização, via execução direta ou parcerias, em que o privado assume a direção das políticas no ambiente escolas e também as executa através do estabelecimento de metas, gestão gerencial, definição de conteúdos e formação de professores. Nos casos estudados, eram os sujeitos vinculados a ideias empresariais que estavam mais atuantes; no entanto, nos últimos anos propostas vinculadas ao neoconservadorismo têm também disputado a pauta da educação, como o projeto Escola sem Partido e a Base Nacional Curricular Comum (BNCC). Neste artigo, trataremos do processo de elaboração da BNCC. 


\section{A BASE NACIONAL COMUM CURRICULAR}

A Base Nacional Comum Curricular passou a ser uma demanda da Lei de Diretrizes e Bases da Educação Nacional e uma agenda do Plano Nacional de Educação. O debate sobre a BNCC ganhou força em 2014 quando o Ministério da Educação (MEC) a retomou para a construção dos direitos de aprendizagem para a educação básica, embora a base aprovada pelo CNE a partir do documento do MEC, tenha consolidado a proposta de Base Nacional Comum Curricular, que tomou o lugar de uma concepção de Base Comum Nacional.

Houve uma inflexão dos conceitos presentes entre a primeira versão e a que foi aprovada pelo CNE em 2017; exemplo disso, é o conceito de base nacional comum e base nacional curricular comum, direitos de aprendizagem e competências e habilidades, ou seja, a própria concepção curricular que norteia a base.

A tramitação que ocorreu a partir de 2014 com consensos e dissensos a respeito de uma base nacional comum e suas três versões, contou numa primeira fase com a participação de professores e especialistas de universidades através de consulta pública na internet, que resultou na primeira versão. Em 2016, a segunda versão do documento da BNCC foi disponibilizada e submetida à discussão em seminários realizados pela União Nacional dos Dirigentes Municipais de Educação (Undime) e pelo Conselho Nacional de Secretários de Educação (Consed). Nesse período, foi constituído um Comitê Gestor do MEC para receber as sugestões dos seminários.

Cabe observarmos que os interesses privados conduzidos pelo Movimento pela Base, coordenado pela Fundação Lemann, por meio do Lemann Center, vinculado à Universidade de Stanfort-US A, buscou especialistas, ligados ao Comum Core americano, para revisar a primeira e segunda versão da base. Uma das revisões, assinada por David Planke, afirmava que:

O processo de obtenção de aprovação para a BNC já começou a despertar oposição política, e isso pode intensificar-se à medida que a adoção e a implementação se aproximem. Se bem conduzida, a revisão nacional do projeto da BNC, ora em curso, pode ajudar a minimizar algumas das controvérsias em torno dos novos padrões (LEMANN CENTER 2016, p.3).

O próprio revisor já alertava para uma possível oposição à base, a partir da experiência americana. A instituição do Comitê Gestor do MEC (Portaria 790/2016 - BRASIL, 2016), contemplou apenas integrantes das secretarias do Ministério, que foram os responsáveis pelas definições e diretrizes que deram origem à terceira versão a partir das revisões de integrantes internacionais, como 
The Curriculum Foundation, instituição inglesa, Accara, instituição australiana e Phill Daro e Susan Pimentel que atuaram no Comonn Core americano, além de Sheila Byrd Carmichael, que assinam a avaliação da BNCC (LEMANN CENTER, 2016).

A proposta da terceira versão, diferente das anteriores, já excluía o Ensino Médio e trazia uma ruptura com a ideia de educação básica. O CNE promoveu uma audiência em cada uma das cinco regiões do Brasil de junho a setembro de 2017, da qual participaram entidades, professores e interessados. De setembro a dezembro de 2017, a base nacional comum curricular tramitou no CNE de forma não transparente e foi aprovada desconsiderando a construção já produzida pelas instituições educacionais comprometidas com a educação pública de qualidade social e sob forte resistência de três conselheiras, representantes de entidades nacionais, que votaram contra a BNCC, assim como diversas instituições e associações de docentes e pesquisadores manifestaram sua oposição a BNCC. A aprovação de uma política pública de forma antidemocrática, sem transparência e sem ampla discussão com a sociedade brasileira revela o modus operandi dos sujeitos individuais e coletivos que fazem parte, tanto de instituições consideradas públicas, quanto privadas.

Conservadores e neoliberais atuam em grupos organizados formados por instituições privadas na forma de institutos, ONGS, fundações ligadas ao mercado (FIGURA 1), quanto por grupos conservadores, religiosos, liberais, ligados ao Congresso Nacional e outros constituídos por think thanks nacionais e internacionais neoconservadores (FIGURA 2).

O ambiente criado nas eleições de 2014 no Brasil, elegendo um congresso conservador, ocupando posições estratégicas na Câmara dos Deputados, foi propício para o avanço de tais ofensivas. Representados majoritariamente pelas bancadas evangélica, ruralista, empresarial e por policiais, influenciam nas pautas e atuam no que Apple (2002) chama de 'coalizão conservadora' nas agendas do país. Após o impeachment em 2016, protagonizada por essa coalizão, a situação é agravada, iniciando o processo de desmantelamento das políticas sociais dos governos anteriores, entre elas, educação, saúde e seguridade social.

\section{OS MOVIMENTOS PELA BASE NACIONAL COMUM CURRICULAR}

O Movimento pela Base Nacional Comum (MBNC) que coordenou esse processo, num primeiro momento sem a presença do MEC, apresentou-se como um grupo não governamental de profissionais e pesquisadores da educação que atuava, desde 2013, para facilitar a construção de uma base de qualidade. Esse 
movimento foi patrocinado pela Fundação Lemann em conjunto com outras instituições públicas e privadas com o objetivo de direcionar a política educacional brasileira a partir de um projeto hegemônico para a educação.

Em 2013, uma delegação brasileira participou, em caráter de Missão Oficial a convite da Fundação Lemann, do Seminário Internacional "Liderando Reformas Educacionais: Fortalecendo o Brasil para o Século XXI", realizado na Universidade de Yale, em abril de 2013, nos Estados Unidos, segundo Requerimento 227/2013/CE (Câmara de Educação). Nesse seminário o tema foi o Common Core americano e, segundo o Deputado Alex Canziani, em discurso na Câmara dos Deputados "esse debate queremos trazer para o Brasil. Tratase do currículo único para a educação brasileira. A ideia é que nós possamos, através dos secretários estaduais de educação, através dos secretários municipais, do próprio MEC, fazer uma discussão sobre currículo" (BRASIL, 2013).

\section{FIGURA 1 - Sujeitos coletivos do Movimento pela Base}

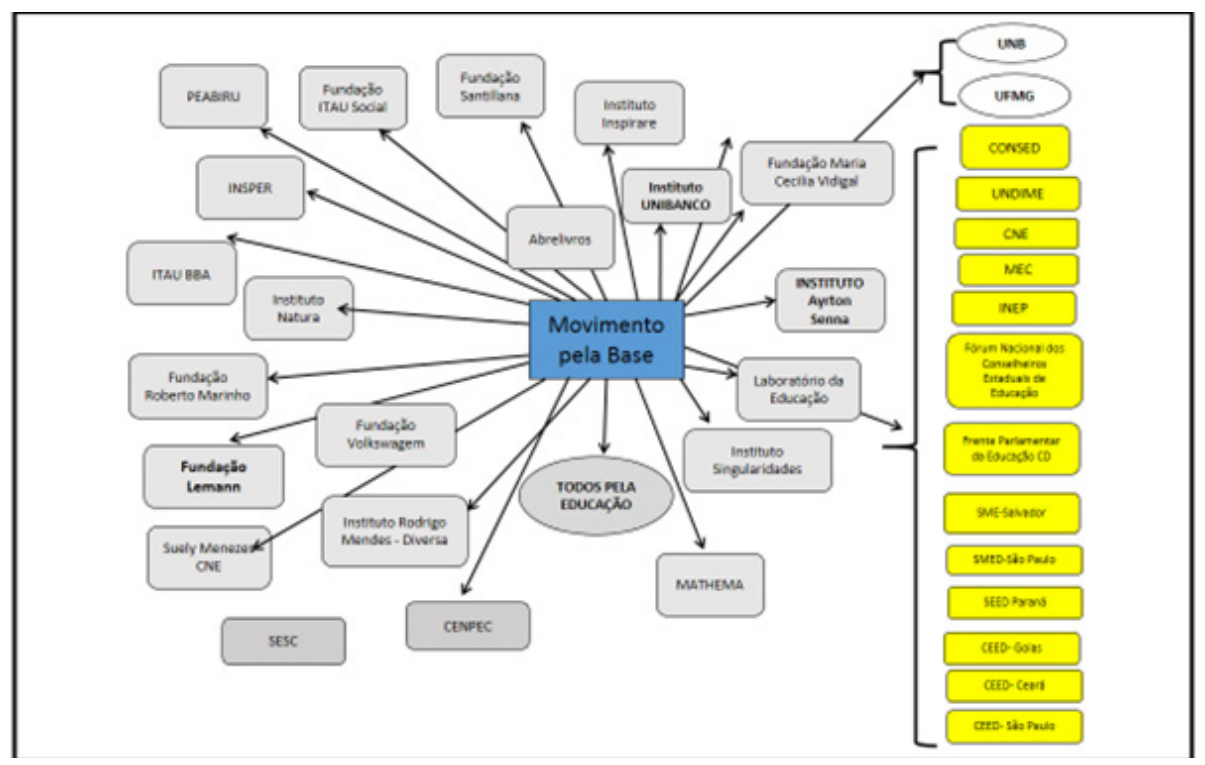

Entre os agentes privados, estão instituições que produzem materiais didáticos como Fundação Santillana e Abrelivros, Itaú-Unibanco, Instituto Ayrton Senna, Insper, Fundação Roberto Marinho, Instituto Natura e o Movimento Todos pela Educação, entre outros. Entre os agentes públicos estão secretarias ligadas a governos do PSDB como São Paulo, Salvador, Goiás, Paraná, a Undime, representante dos secretários municipais de educação do país e o Consed, 
que representa os secretários estaduais de educação, além do INEP, do MEC e Conselho Nacional de Educação. Constitui-se num grupo hegemônico, que representa uma classe, em relação a um projeto educacional para o país.

Conforme Peroni e Caetano (2015), esse grupo é composto de grandes instituições privadas que têm-se articulado com instituições educacionais globais, visando a promover mudanças na educação dos países, especialmente no currículo e avaliação e, consequentemente, na formação docente, entre outros. Essas instituições propuseram conteúdos à base, como exemplo, o Instituto Ayrton Senna, que apresentou recomendações para o desenvolvimento de competências socioemocionais.

O Instituto Ayrton Senna (IAS) criou em 2015, o laboratório eduLab21. Esse laboratório estuda as competências socioemocionais e propõe o SENNA, avaliação dessas competências. Atua como think thank promovendo workshops, seminários em parceria com instituições do Movimento pela Base, Consed, Undime, Unesco e OCDE, visando a influenciar a BNCC. O IAS vem atuando no conteúdo da proposta da base e na direção das políticas públicas conforme informações do site .

A Associação Nacional de Pós-graduação em Educação - ANPED manifesta-se rejeitando a proposta do SENNA:

Trata-se de rejeitar a adoção, como política pública, do programa de medição
de competências socioemocionais, denominado SENNA (Social and Emotional
or Noncognitive Nationwide Assessment), produto de iniciativa do Instituto
Ayrton Senna em parceria com a OCDE (Organização para a Cooperação e
Desenvolvimento Econômico). Essa perspectiva está colocada na medida em
que se tem a presença do Ministério da Educação (MEC) apoiando a realização
de seminários em que tal proposta foi divulgada, [...] para a criação do Programa
de Formação de Pesquisadores e Professores no Campo das Competências
Socioemocionais (ANPED, 2014, p.1).

A entidade questiona, ainda, o que significa uma instituição privada definir o "conteúdo da educação" por meio de avaliações socioemocionais. (Ibidem).

Estudo apresentado por Smolka et all (2015), mostra as controvérsias relacionadas aos fundamentos epistemológicos do construto Big Five (competências socioemocionais) e se posicionam contra a adoção e a implementação de tal proposta como política pública.

No documento final da BNCC, intitulado Educação é a base, com o apoio do MPB (BRASIL, 2017) apresentam-se as competências gerais que se tornaram obrigatórias para os sistemas e escolas: conhecimento; pensamento cientifico, 
crítico e criativo; repertório cultural; comunicação; cultura digital; trabalho e projeto de vida; argumentação, autoconhecimento e autocuidado; empatia e cooperação; responsabilidade e cidadania. Percebemos que na descrição das competências há claramente a orientação para as competências socioemocionais, além do empreendedorismo, educação financeira e meritocracia. ${ }^{6}$

Observe-se, também, que essa é a primeira vez que o MEC apresenta uma proposta oficial, afirmando que ela será obrigatória, contrariando dispositivo constitucional que garante o "pluralismo de ideias e de concepções pedagógicas", como direito do ensino brasileiro (art. 206, III, Constituição Federal, BRASIL, 1988).

O processo de construção da BNCC foi incorporando bandeiras do movimento empresarial e por outro, o financiamento do grande capital alinhados à OCDE. Portanto, temos instituições empresarias que atuam através de programas na Educação Básica, prestadores de todo tipo de serviço para a educação e gerentes dispostos a fazer parte desse grupo para gerenciar os processos e serviços oferecidos, direcionando a educação. Adrião (2017) aborda como a Educação Básica se tornou um novo negócio na educação.

Em 2016, a Fundação Lemann assumiu a direção das revistas Nova Escola e Gestão Escolar. A partir de 2017, a Nova Escola e o Google anunciaram uma parceira de produção de planos de aula estruturados e alinhados à BNCC disponibilizados a professores. O acordo com a Google envolve, também, produzir um canal de conteúdo educacional para o ensino médio no YouTube chamado YouTube Edu. Em 2017, a Fundação Lemann e a Omidyar Network. anunciaram uma parceria para desenvolver soluções tecnológicas que facilitassem a implementação da BNCC por meio da tecnologia ${ }^{8}$. A Khan Academy, plataforma de educação digital, ensina matemática, ciências e economia, entre outras áreas, com aulas gravadas e exercícios na tela do computador para alunos. Segundo Mizne quem compra o hardware é a escola. "A fundação banca a plataforma, a formação do professor e o acompanhamento" (MIZNE, 2015).

Para o MEC, a BNCC será a referência para a formação de professores, adequação de livros e recursos didáticos, alinhamento nas avaliações e será utilizada para provimento de infraestrutura escolar, ou seja, é a espinha dorsal da reforma da educação.

$6 \quad$ Ver Adrião, 2017.

7 Segundo o site da fundação, as soluções podem ter impacto direto na sala de aula e servir para professores ou alunos, mas também podem apoiar a gestão escolar, elaboração de currículos, rotina de secretarias de educação e envolvimento dos pais e responsáveis, entre outras questões (https://fundacaolemann.org.br/ noticias/parceria-foca-em-tecnologias-para-bncc). 


\section{A BNCC E OS NEOCONSERVADORES}

$\mathrm{Na}$ disputa pela BNCC entre os sujeitos que despontam estão os neoconservadores, que defendem o regresso aos valores tradicionais, à moralidade e a religião. Esses grupos baseiam suas posições na educação através de visões fundamentadas na autoridade bíblica, moral cristã, as questões de gênero e o papel da família.

Grupos conservadores ganharam centralidade na discussão da BNCC, como mostra a figura 2, incluindo a censura aos livros didáticos. No caso do Brasil, os neoliberais e conservadores vêm-se articulando a longa data. Embora com pautas diferentes, quando os interesses são comuns, eles se unem, como foi o caso da BNCC em temas ligados a gênero, sexualidade, família. Por outro lado, políticos das bancadas religiosas se aproximam do ideal neoconservador. Todos eles defendem políticas de austeridade e ajuste fiscal e um discurso moralista baseado em pressupostos cristãos, como a defesa da família. Nem sempre esses grupos estão em concordância, ainda que se tenham aproximado nos últimos tempos a fim de articular pautas comuns como é o caso do Escola sem Partido, Movimento Brasil Livre, Estudantes pela Liberdade, Vem pra Rua e Revoltados on line. Muitos deles financiados pela Atlas Network (Amaral, 2015), uma conexão transnacional dessas entidades que, na prática, conformam uma mesma forma de organização de ideias e ligações com instituições nacionais que passaram a atuar de forma mais orgânica a partir de 2014 com o enfraquecimento político do bloco que ocupava a Presidência da República. Em comum, a defesa de privilégios das elites neoliberais e neoconservadores, que defendem o fim dos programas sociais implementados e praticados nos governos Lula e Dilma (2003-2016) e a redução de direitos dos trabalhadores, seguindo a dinâmica do Estado Mínimo não interventor. E, para isso, contam com apoio da grande mídia conservadora brasileira. 


\section{FIGURA 2 - Os sujeitos neoconservadores e a BNCC}

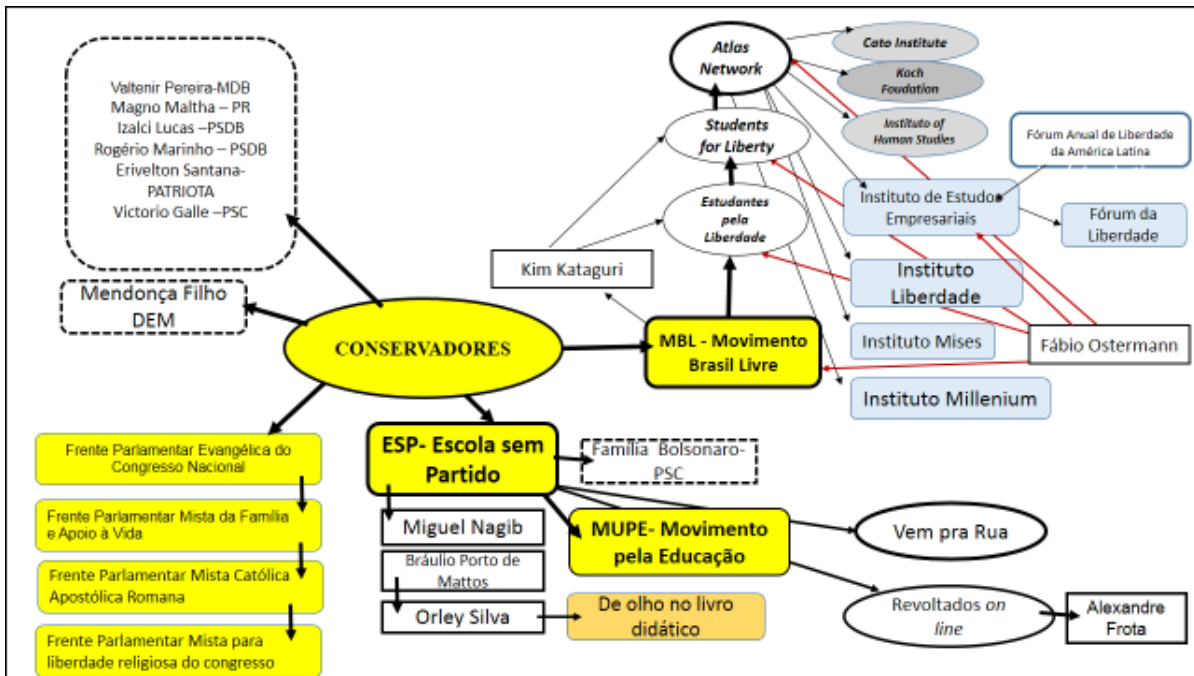

A Figura 2 apresenta grupos que vêm influenciando agendas educacionais, incluindo a construção da BNCC. À esquerda, a classe política representada pelas frentes parlamentares ligadas a instituições religiosas, o ex-ministro da Educação Mendonça Filho, representante da ala conservadora e privatista e acima, alguns dos deputados e um senador apoiadores do Escola sem partido e outras pautas de gênero. Ao tomar posse, uma das primeiras agendas do então ministro foi receber integrantes do grupo Revoltados on line, Alexandre Frota, em 25 de maio de 2016, cuja pauta foi o combate à "doutrinação" política, religiosa e sexual e apoio ao Escola sem Partido?.

Conforme relatórios da Comissão de Educação da Câmara dos Deputados em 2014, 2015, 2016 e 2017, o debate sobre o ESP começou a tramitar na Câmara dos deputados em 2014, através do requerimento 387/2014, do deputado Izalci Lucas, que solicitou Audiência Pública visando discutir o tema 'Doutrinação Política e Ideológica nas Escolas'. Em março de 2015, Bráulio Porto de Matos, professor da UNB e atual vice-presidente do Escola sem Partido, foi à Comissão de Educação da Câmara para falar sobre a doutrinação política e ideológica nas escolas. Em outubro de 2015, a Comissão de Educação realizou audiência pública para debater o assédio ideológico nas escolas brasileiras de Educação Básica, cujo autor foi o deputado Rogério Marinho, que justificou a realização 
do debate "afirmando que crianças e adolescentes têm sofrido doutrinação político-partidária dentro da sala de aula, contrariando a Constituição Federal e prejudicando o direito de aprender", conforme o Portal Câmara - notícias, em 6/10/2015. Participaram do encontro uma representante da União Nacional dos Dirigentes Municipais de Educação (Undime); o presidente da Assembleia de Deus Vitória em Cristo, Silas Malafaia; o professor da Universidade de Brasília, Bráulio Pôrto De Matos; o presidente da Confederação Nacional dos Trabalhadores em Educação, Roberto Franklin de Leão; o professor, escritor e jornalista, Olavo de Carvalho; o coordenador do Movimento Escola sem Partido, Miguel Nagib; o então jornalista e colunista da Revista Veja, Rodrigo Constantino e o professor da Universidade de Brasília, Erlando da Silva Rêses (BRASIL,2015).

Em 2016, o deputado Rogério Marinho requereu Reunião de Audiência Pública com especialistas para discussão da Base Nacional Comum Curricular BNCC acerca da área de Ciências Humanas, com a presença dos Senhores Marco Antonio Villa - historiador; Demétrio Magnoli - geógrafo; Ronaldo Vainfas historiador; Bráulio Tarcísio Porto de Matos, Professor da UNB; e Miguel Nagib - Movimento Escola Sem Partido e que se transformou em Seminário realizado em 31/05/2016. Em conjunto com os requerimentos datados de 2015 e 2016, destaca-se a presença como debatedores de Orley José da Silva, que coordena um blog intitulado 'De olho no livro didático' cujo objetivo é denunciar questões de gênero e questões que o autor considera ideológicas nos livros didáticos; Bráulio Porto de Matos, Professor de Sociologia da UnB e vice-presidente do Escola sem Partido, além do Pe. José Eduardo Silva, Professor Universitário da Faculdade São Bento/SP (BRASIL 2015,2016).

Também consta no mesmo relatório que foi solicitado pelo deputado Bacelar a realização de Audiência Pública na Comissão Permanente de Educação, para tratar da exclusão das questões de gênero nos Planos Nacional, Estaduais e Municipais de Educação, aprovado em 08/06/2016. Nesse mesmo ano, foi apresentada a Indicação 780/16 de autoria dos deputados Valtenir Pereira, exdeputado Renato Simões e ex-deputada Jaqueline Roriz, que sugeriam a inclusão obrigatória, nos currículos do Ensino Fundamental e Ensino Médio, das disciplinas Organização Social e Política do Brasil e Educação Moral e Cívica, bem como de conteúdos referentes ao período da ditadura militar no Brasil e à violação dos Direitos Humanos, que foi arquivado. O senado federal também apresentou projeto de lei que visava incluir entre as diretrizes e bases da educação o "Programa Escola sem Partido", através do PL 193/2016.Foi negado pela comissão de educação do senado e Magno Maltha retirou o PL em novembro de 2017. Na Câmara, o PL 7180/2014 de autoria do deputado Erivelton Santana foi retomado e debatido em 4 de abril de 2018 cujo conteúdo visava a incluir entre 
os princípios do ensino o respeito às convicções do aluno e de seus responsáveis, dando precedência aos valores de ordem familiar sobre a educação escolar nos aspectos relacionados à educação moral, sexual e religiosa (BRASIL, 2016, 2017). Destacamos que ainda estão em tramitação dezenas de projetos do Escola Sem Partido nos níveis municipais e estaduais em todo país. São projetos que visam a impedir o debate de gênero e sexualidade e censuram a liberdade de reflexão crítica, dos preceitos de um estado laico e democrático, uma verdadeira mordaça e assédio, imposto aos professores e à juventude. Em oposição aos projetos Escola sem Partido, professores de vários estados e municípios do Brasil lançaram a Frente Escola sem Mordaça por uma educação democrática, além de outros movimentos a favor da educação pública e laica.

Na Figura 2, à direita, está o MBL que surgiu em 2013, e as instituições nacionais e internacionais nas quais estão ligados de forma individual ou coletiva. E entre os dois, está o Projeto Escola sem Partido, contando com o apoio do MBL, que prega liberdades individuais, mas inclui em suas agendas pautas conservadoras.

Destacamos que "muitos membros do Movimento Brasil Livre passaram pelo programa de treinamento do Atlas Network, a Atlas Leadership Academy, e estão agora aplicando o que aprenderam no solo em que eles vivem e trabalham", dizia artigo publicado no site da entidade ( HOEVELER,2016, p.34). Os gaúchos Ostermann e Anthony Ling, além do mineiro Juliano Torres são fundadores do EPL, a versão local do Students for Liberty, organização-chave na articulação entre os think tanks conservadores americanos - especialmente os que se definem como libertários - e a juventude "antipopulista" da América Latina. Alejandro Chafuen, presidente da Atlas Network desde 1991, é o seu mentor (AMARAL, 2015).

A Atlas Network (nome fantasia da Atlas Economic Research Foundation desde 2013) é, conforme Amaral (2015), uma espécie de metathink tank, especializada em fomentar a criação de outras organizações libertaristas no mundo, com recursos obtidos com fundações parceiras nos Estados Unidos e/ou canalizados dos think tanks empresariais locais para a formação de jovens líderes, principalmente na América Latina e Europa oriental. Os recursos destinados para atividades fora dos Estados Unidos foram de US\$ 6,1 milhões, dos quais US\$2,8 milhões para a América Central e US\$ 595 mil para a América do Sul. Os Estudantes pela Liberdade, é uma organização que nasceu dentro da Atlas em 2012. Já a Rede Students for Liberty em franca expansão, conta com recursos da John Templeton, com orçamento de mais de US\$ 1 milhão (AMARAL, 2015). 
A missão dessas instituições além de influenciar e desestabilizar sistemas democráticos, especialmente na América Latina, é a formação de lideranças jovens que possam expandir sua ação nos diferentes países. Eles atuam em redes dentro de redes, possuem altos investimentos, patrocínios e utilizam as redes sociais para impor seus pensamentos conservadores e liberais.

\section{CONSIDERAÇÕES FINAIS}

O Brasil não tem um histórico democrático e a privatização do público é uma realidade "naturalizada" em nossa cultura. No entanto, no período pósditadura, em um processo de correlação de forças com essa lógica historicamente instaurada, no período de democratização, iniciou-se um movimento de repensar o público, o Estado, com a participação efetiva da sociedade. Assim, por um lado, avançamos no acesso à educação, mas, por outro, há um avanço da privatização do público e de naturalização das perdas da democratização da educação.

Quando avançamos alguns passos no processo democrático, em um processo de correlação de forças, o setor empresarial e neoconservador se reorganiza, em uma grande ofensiva, para retomar a direção política da educação.

Como apresentamos, o interesse pela BNCC brasileira envolve tanto neoliberais quanto conservadores. O centro dessa disputa é um projeto de nação e de formação do trabalhador, em que a educação passa a ser o alvo dos interesses do grande capital.

Nesse processo, a disputa pelos fundos públicos é a prioridade desses grupos, que vêm desqualificando, sistematicamente, as escolas e as redes públicas de ensino para que eles se apresentem como "salvadores" preferenciais da qualidade da educação brasileira, seja vendendo materiais, assessorias especializadas, assumindo a gestão de escolas ou, até os programas das secretarias de educação.

O importante é que os direitos sociais - como o direito à educação de qualidade - comecem a ser considerados como "privilégios", que, para serem obtidos precisam de "serviços" e atendimentos especiais e estes, no mercado, têm um custo. E quanto melhor qualidade se desejar, mais alto é seu preço.

Para que esse modelo se consolide há um pressuposto: a adesão ou o silêncio - espontâneos ou forçados - de professores, pais e alunos, sindicatos e associações científicas. Como isso não é tão fácil, são necessárias iniciativas nacionais como os projetos de Escola sem Partido, ou a adoção de currículos únicos, no caso, a BNCC, nos quais sejam eles os proponentes dos conteúdos. No primeiro momento para convencer e no segundo, para calar. 
Não nos iludamos: a luta é longa e só há um jeito de contê-los: envolver alunos e professores nessa discussão, chamar os pais e responsáveis para analisar e problematizar os conteúdos curriculares que vêm sendo propostos, politizar a discussão sobre formação de professores e sobre a escola que queremos para nossos filhos e para o Brasil.

A função das escolas está em jogo e a soberania nacional, sem ciência, tecnologia, e autonomia de pesquisa corre sérios riscos. A ação unitária nossa é necessária agora! Vamos juntos!

\section{REFERÊNCIAS}

ADRIÃO. Theresa. A privatização dos processos pedagógicos: Grupos editoriais e os negócios na educação básica. In: Maringoni, G. (org). O negócio da Educação. São Paulo: Olho Dágua e Fepesp. 2017. p. 129-144.

AMARAL. Marina. A nova roupa da direita. A publica jornalismo investigativo. 23/6/2015. Disponível em: <https://apublica.org/2015/06/a-nova-roupa-dadireita/>. Acesso em: 20 jun. 2018.

ANPED. Associação Nacional de Pós graduação e Pesquisa em Educação. Carta Aberta a comunidade acadêmica e aos representantes de secretarias e órgãos do Ministério da Educação sobre Avaliação em larga escala de habilidades não cognitivas de crianças e jovens.6/11/2014. Disponível em: <http://www.anped.org.br/sites/default/files/resources/carta_aberta_ avaliac_a_o_habilidades_na_o_cognitivas.pdf> Acesso em: 15 jun. 2018.

APPLE, Michael. Endireitar a educação: as escolas e a nova aliança conservadora. Currículo sem Fronteiras, v. 2, n. 1, jan./jun. 2002. Disponível em: http:// CurriculosemFronteiras/2002/vol2/no1/4.pdf. Acesso em: 26 jun. 2018.

BOITO JR. Armando. Os atores e o enredo da crise política. In: JINKINGS. Ivana, KLIN. Doria; CLETO. Murilo. Porque gritamos Golpe. Para entender o impeachment e a crise política no Brasil. São Paulo: Boitempo Editorial, 2016.

BRASIL. CÂMARA DOS DEPUTADOS.COMISSÃO DE EDUCAÇÃO. Relatório de Atividades 2017. Brasília, janeiro de 2018. 
BRASIL.CAMARA DOS DEPUTADOS. Portal Câmara Notícias. Disponível em: <http://www2.camara.leg.br/camaranoticias/noticias/EDUCACAO-ECULTURA/497504-COMISSAO-DE-EDUCACAO-DEBATE-ASSEDIOIDEOLOGICO-NAS-ESCOLAS.html>. Acesso em: 23 jun. 2018.

BRASIL. CÂMARA DOS DEPUTADOS.COMISSÃO DE EDUCAÇÃO. Relatório de Atividades 2016. Brasília, janeiro de 2017.

BRASIL. CÂMARA DOS DEPUTADOS.COMISSÃO DE EDUCAÇÃO. Relatório de Atividades 2015. Brasília, janeiro de 2016.

BRASIL. CÂMARA DOS DEPUTADOS.COMISSÃO DE EDUCAÇÃO. Relatório de Atividades 2014. Brasília, janeiro de 2015.

BRASIL. CÂMARA DOS DEPUTADOS.COMISSÃO DE EDUCAÇÃO. Relatório de Atividades 2014. Brasília, janeiro de 2013.

BRASIL. CONSTITUIÇÃO, 1988. Constituição da República Federativa do Brasil: Promulgada em 5 de outubro de 1988. Organização do texto: Juarez de Oliveira. 4 ed. São Paulo: Saraiva, 1990. 168p.

FERNANDES, Florestan. Nova República? Rio de Janeiro: Jorge Zahar, 1985.

A Revolução burguesa no Brasil, 3. ed. Rio de Janeiro: Editora Guanabara. 1987

HARVEY, David. O Neoliberalismo: história e implicações. São Paulo: Loyola, 2008.

HARVEY, David. Condição pós-moderna. 4. ed. São Paulo: Loyola, 1989.

HOEVELER, Rejane. A direita transnacional em perspectiva histórica: o sentido da nova direita brasileira. In DEMIER. Felipe; HOEVELER, Rejane(orgs). A onda conservadora. Ensaio sobre os atuais tempos sombrios no Brasil. Rio de Janeiro: Editora Maured, 2016. 
KAYSEL, André. Regressando ao regresso: elementos para uma genealogia das direitas brasileiras. In CRUZ, Sebastião, KAYSEL, André, CODAS Gustavo (org). Direita Volver o retorno da direita e o ciclo econômico brasileiro. São Paulo: Fundação Perseu Abramo, 2015.

LEMANN CENTER. Base Nacional Comum Curricular 2016. Parte I: Implementação da BNC: Lições do "Common Core" Por David Plank 17 de Fevereiro de 2016. Disponível em http://movimentopelabase.org.br/wpcontent/uploads/2016/06/Implementacao-david-plank-portg.pdf.Acesso em 26 jun 2018.

LOWY. Michael. Da tragédia à farsa: o golpe de 2016 no Brasil. In: JINKINGS. Ivana, KLIN. Doria; CLETO. Murilo. Porque gritamos Golpe. Para entender o impeachment e a crise política no Brasil. São Paulo: Boitempo Editorial, 2016.

MÉSZÁROS, István. Para além do Capital. São Paulo: Boitempo Editorial; Campinas: Editora da UNICAMP, 2002.

MIGUEL. Luis Felipe.A democracia na encruzilhada. In: JINKINGS. Ivana, KLIN. Doria; CLETO. Murilo. Porque gritamos Golpe. Para entender o impeachment e a crise política no Brasil. São Paulo: Boitempo Editorial, 2016.

MIZNE. Denis. Como Jorge Paulo Lemann, o homem mais rico do Brasil, pretende mudar a educação no país. In Guilherme Felitti . Revista Época Negócios.10/01/2015.Disponível em https://epocanegocios.globo.com/ Informacao/Acao/noticia/2015/01/como-jorge-paulo-lemann-o-homem-maisrico-do-brasil-pretende-mudar-educacao-no-pais.html.Acesso em 27 jun 2018.

MORAES. Reginaldo C. A organização das células neoconservadoras de agitprop:o fator subjetivo da contrarrevolução. In CRUZ, Sebastião, KAYSEL, André, CODAS Gustavo (org). Direita Volver o retorno da direita e o ciclo econômico brasileiro. São Paulo: Fundação Perseu Abramo, 2015.

OLIVEIRA, J. B. A.; CASTRO, C. de M. (Org.). Ensino fundamental \& competitividade empresarial: uma proposta para ação de governo. 1. ed. São Paulo: Instituto Herbert Levy, 1993. 
PERONI V. M; CAETANO, M. R. O público e o privado na educação Projetos em disputa? Revista Retratos da Escola, Brasília, v. 9, n. 17, p. 337-352, jul./ dez. 2015.

PERONI, V.M.; CAETANO, M.R.; LIMA,P. Reformas educacionais de hoje. In: Revista Retratos da Escola, As implicações para a democracia Revista Retratos da Escola, Brasília, v. 11, n. 21, p. 415-432, jul./dez. 2017.

As Implicações da relação público-privada para a democratização da educação no Brasil. Tese (promoção a Professor Titular da Carreira do Magistério Superior), UFRGS. 2016.

SMOLKA, Ana Luiza Bustamante; LAPLANE, Adriana Lia Friszman de; MAGIOLINO, Lavinia Lopes Salomão and DAINEZ, Débora. O problema da avaliação das habilidades socioemocionais como política pública: explicitando controvérsias e argumentos. Educação e Sociedade. 2015, vol.36, n.130, pp.219242 .

THOMPSON, Edward P. A formação da classe operária inglesa. Trad. de Denise Bottmann. 2. ed. Rio de Janeiro: Paz e Terra, 1987. 3 v.

THOMPSON, E. P. A miséria da teoria ou um planetário de erros. Rio de Janeiro: Zahar, 1981.

VIEIRA, Evaldo. O Estado e a sociedade civil perante o ECA e a LOAS. Serviço Social \& Sociedade, São Paulo, n. 56, p. 9-23, mar. 1998.

WOOD, Ellen M. Democracia contra o capitalismo: a renovação do materialismo histórico. São Paulo: Boitempo Editorial, 2003.

Sites:

https:// fundacaolemann.org.br

https://www.institutoayrtonsenna.org.br/pt-br

https://www.institutoliberal.org.br 
VERA MARIA VIDAL PERONI é doutora em Educação e professora da Universidade Federal do Rio Grande do Sul (UFRGS) nos cursos de graduação e pós-graduação em educação. Coordena grupo de pesquisa sobre a relação entre o público e o privado na educação (GPRPPE). Sua pesquisa mais recente trata das "Implicações da relação público-privada para a democratização da educação na América Latina: Uruguai, Argentina, Venezuela, Chile, Bolívia e Brasil Implicações da relação público-privada para a democratização da educação". E-mail: veraperoni@gmail.com

MARIA RAQUEL CAETANO Possui graduação e licenciatura em Pedagogia com habilitação em Supervisão Escolar pelo Centro Universitário FEEVALE (1988) e Mestrado em Educação pela Pontifícia Universidade Católica do Rio Grande do Sul (2002). .Doutora em Educação pela Universidade Federal do Rio Grande do Sul(2013)na linha de Gestão e Politicas Educacionais.Pesquisa as relações entre o público e o privado na educação e também a formação de professores na educação básica e profissional. Professora do Instituto Federal de Educação, Ciência e Tecnologia, atua no Campus Sapucaia do Sul. E-mail: caetanoraquel2013@gmail.com

LISETE REGINA GOMES ARELARO é Pedagoga e Doutora em Educação e professora Titular Sênior da Faculdade de Educação da USP. Foi professora e diretora de escola nos ensinos fundamental e médio. Fez parte da equipe do Prof. Paulo Freire na Secretaria Municipal de Educação de São Paulo (1989/92) e foi Secretária de Educação, Cultura, Esporte e Lazer em Diadema/SP 1993/96 e 2001/02), Diretora da Faculdade de Educação da USP (2010/2014), Presidente do Fórum Nacional de Faculdades e Centros de Educação Públicos (FORUMDIR - 2012/2014) e presidente da Associação Nacional de Pesquisa em Financiamento da Educação (FINEDUCA - 2015/2017)., e pesquisadora na área de Política Educacional, Planejamento e Avaliação Educacional, Financiamento da Educação Básica e Educação Popular. E-mail: liselaro@usp.br

Recebido em setembro de 2018 Aprovado em fevereiro de 2019 